\title{
Nicotine Therapy in Adulthood Reverses the Synaptic and Behavioral Deficits Elicited by Prenatal Exposure to Phenobarbital
}

\author{
Avital Beer', Theodore A Slotkin ${ }^{2}$, Frederic J Seidler ${ }^{2}$, Justin E Aldridge ${ }^{2}$ and Joseph Yanai*,I,2 \\ 'The Ross Laboratory for Studies in Neural Birth Defects, Department of Anatomy and Cell Biology, The Hebrew University-Hadassah Medical \\ School, Jerusalem, Israel; ${ }^{2}$ Department of Pharmacology and Cancer Biology, Duke University Medical Center, Durham, NC, USA
}

\begin{abstract}
A major objective in identifying the mechanisms underlying neurobehavioral teratogenicity is the possibility of designing therapies that reverse or offset drug- or toxicant-induced neural damage. In our previous studies, we identified deficits in hippocampal muscarinic cholinergic receptor-induced membrane translocation of protein kinase $C$ (PKC) $\gamma$ as the likely mechanism responsible for adverse behavioral effects of prenatal phenobarbital exposure. We therefore explored whether behavioral and synaptic defects could be reversed in adulthood by nicotine administration. Pregnant mice were given milled food containing phenobarbital to achieve a daily dose of $0.5-0.6 \mathrm{~g} / \mathrm{kg}$ from gestational days 9-18. In adulthood, offspring showed deficits in the Morris maze, a behavior dependent on the integrity of septohippocampal cholinergic synaptic function, along with the loss of the PKC $\gamma$ response. Phenobarbital-exposed and contro mice then received nicotine $(10 \mathrm{mg} / \mathrm{kg} /$ day) for 14 days via osmotic minipumps. Nicotine reversed the behavioral deficits and restored the normal response of hippocampal PKC $\gamma$ to cholinergic receptor stimulation. The effects were regionally specific, as PKC $\gamma$ in the cerebellum was unaffected by either phenobarbital or nicotine; furthermore, in the hippocampus, PKC isoforms unrelated to the behavioral deficits showed no changes. Nicotine administration thus offers a potential therapy for reversing neurobehavioral deficits originating in septohippocampal cholinergic defects elicited by prenatal drug or toxicant exposures.

Neuropsychopharmacology (2005) 30, 156-165, advance online publication, 20 October 2004; doi: I0.1038/sj.npp. 1300582
\end{abstract}

Keywords: Morris water maze; nicotine therapy; phenobarbital; PKC isoforms; prenatal exposure; septohippocampal cholinergic innervation

\section{INTRODUCTION}

Neurobehavioral abnormalities resulting from developmental exposure to drugs or neurotoxicants represent a major societal liability. A great deal of attention has been paid to identifying the mechanisms underlying adverse outcomes of exposures to behavioral teratogens, but relatively less work has focused on utilizing this information to attempt to ameliorate or reverse these defects. One prerequisite for such studies is the identification of specific synaptic and/or cellular mechanisms that represent the critical control point for a given behavioral perturbation, and we have shown in animal models that restoration of normal function is indeed feasible under those circumstances. To date, the best

*Correspondence: Dr J Yanai, The Ross Laboratory for Studies in Neural Birth Defects, Department of Anatomy and Cell Biology, The Hebrew University-Hadassah Medical School, Box 12272, 91 120 Jerusalem, Israel, Tel: + 9722675 8439, Fax: +972 2675 8443,

E-mail: yanai@md.huji.ac.il

Received 3 May 2004; revised 30 July 2004; accepted 18 August 2004 Online publication: 31 August 2004 at http://www.acnp.org/citations/ Npp083104042 10/default.pdf example is provided by the barbiturate, phenobarbital, which targets septohippocampal cholinergic innervation and its related synaptic and behavioral parameters.

Phenobarbital is a neurobehavioral teratogen in humans and animals (Smith et al, 1986; Yanai, 1984; Wallace, 1984) that was formerly used during pregnancy for prophylaxis of neonatal hyperbilirubinemia (Valaes and Harvey-Wilkes, 1990), for epilepsy (Nulman et al, 1999), and for the prevention of subependymal/intraventricular hemorrhage in preterm infants (Arroyo-Cabrales et al, 1998). Like a number of other neuroteratogens (Steingart et al, 2000a, b), phenobarbital's neurobehavioral teratogenic actions converge on the functioning of septohippocampal cholinergic pathways, resulting in a pattern of defective synaptic transmission and attendant hippocampus-related behavioral deficits (Yanai et al, 1996; Steingart et al, 2000a,b). Accordingly, therapies in adulthood that re-establish hippocampal cholinergic function, including suppression of inputs that offset cholinergic activity (Yanai et al, 1989) and grafting of cholinergic precursor cells into the hippocampus (Steingart et al, 2000a,b), offset both the behavioral and neurochemical changes associated with 
the teratogen. These findings provide the rationale for attempting to reverse neuroteratogenicity with a more feasible procedure, namely nicotine therapy.

As a cholinergic agonist, nicotine can substitute for acetylcholine in a situation of impaired function. Nicotine therapy has been applied successfully in humans as well as in animal models for the reversal of cognitive dysfunction associated with surgical lesions or neurodegenerative disorders (Rezvani and Levin, 2001), and can be applied safely and continuously either by transdermal patches in humans (Hanson et al, 2003) or by subcutaneously implanted osmotic minipumps in animals (Slotkin, 1998, 2002). Nicotinic cholinergic receptors crosstalk with muscarinic cholinergic inputs at the level of protein kinase $\mathrm{C}$ (PKC) (Messing et al, 1989; Tuominen et al, 1992), providing a rationale for a mechanistically based reversal of phenobarbital-induced neurobehavioral and synaptic defects.

In the current study, we evaluated the ability of nicotine infusions given in adulthood to reverse the behavioral and synaptic defects evoked by prenatal phenobarbital exposure. For behavioral assessment, we relied on the Morris water maze, which is dependent on the integrity of septohippocampal cholinergic innervation (Shim et al, 2003) and has served as an appropriate behavioral end point in numerous models detailing hippocampal dysfunction. At the synaptic level, we focused on the functioning of muscarinic cholinergic receptors and their control of PKC $\gamma$ activation and translocation to the cell membrane (Steingart et al, 2000b; Yaniv et al, 2004). PKC is specifically implicated in hippocampal learning (Golski et al, 1995; Olds et al, 1990; Wehner et al, 1990), and our earlier work with heroin showed that the desensitization of PKC response, and specifically that of $\mathrm{PKC} \gamma$, to muscarinic receptor stimulation is the principal neurochemical mechanism of their behavioral teratogenicity (Steingart et al, 2000b; Shahak et al, 2003). Given the similarities between heroin and phenobarbital for behavioral outcomes and cholinergic synaptic defects (Steingart et al, 2000a; Yanai et al, 1996), we hypothesized that the same signaling pathway would be targeted by phenobarbital and restored by nicotine. To demonstrate specificity, we have performed a number of comparisons with other $\mathrm{PKC}$ isoforms, regions, and biomarkers. We evaluated changes in $\mathrm{PKC} \alpha$, an isoform that is unrelated to hippocampus-dependent behaviors, and whose translocation from cytosol to cell membrane is not inducible by cholinergic receptor stimulation (Colombo et al, 1997). We also evaluated changes in $\mathrm{PKC} \gamma$ responsiveness in the cerebellum, a target region that is relatively sparse in cholinergic innervation and that should therefore be spared as compared to the hippocampus. Finally, we evaluated biomarkers of cholinergic synaptic integrity and activity, and markers for neural cell damage in the cerebral cortex and brainstem, so as to demonstrate the regional specificity of phenobarbital's effects and nicotine's ability to offset those effects.

\section{MATERIALS AND METHODS}

Female heterogeneous stock (HS/Ibg) mice were exposed to $0.3 \%$ phenobarbital contained in their milled food (net dose of $500-600 \mathrm{mg} / \mathrm{kg}$ per day) on gestational days 9-18 and the offspring were crossfostered by control dams within $24 \mathrm{~h}$ after birth. Animals were weaned on postnatal day (PN) 25 and on PN44 they were implanted with Alzet type 1002 osmotic minipumps (Durect, Cupertino, CA), containing nicotine bitartrate (Sigma, Israel) in bacteriostatic water (Abbott Diagnostics, Abbott Park, IL), set to deliver 10 $\mathrm{mg} / \mathrm{kg}$ of nicotine-free base per day; controls received equivalent concentrations of sodium bitartrate. The effectiveness and details of these treatments have been described in detail in previous work (Steingart et al, 2000a; Yanai and Pick, 1988; Slotkin, 1998; Slotkin, 2002). In keeping with the prior studies, there were no signs of maternal, fetal, or neonatal toxicity or withdrawal. Morris maze testing began on PN53 and continued for 5 days. At 1 day after the behavioral testing (PN58), brains were removed and the hippocampus, cerebellum, cerebral cortex, and brainstem were dissected. The first two regions were taken for analysis of cholinergic-induced translocation/activation of PKC isoforms, whereas the latter two were used for assessment of cholinergic and cell injury biomarkers.

All experiments were designed so that only a single pup from each litter was used in each experimental group in order to prevent bias resulting from litter effects. Both males and females were used in the studies and the possibility of gender effects was considered in the statistical analysis.

The Morris water maze was conducted in an adaptation (Rogel-Fuchs et al, 1994) of the device originally developed for rats (Morris, 1984), using a circular tank $87 \mathrm{~cm}$ in diameter, containing water $\left(24^{\circ} \mathrm{C}\right)$ rendered opaque by adding powdered milk, and a platform $8 \times 10 \times 9 \mathrm{~cm}$ $(1 \times w \times h)$, placed $1 \mathrm{~cm}$ below the surface of the water. In the place test, the mice were given two blocks of four trials on each day for four consecutive days (Nilsson et al, 1987). On all trial days, each mouse was given $60 \mathrm{~s}$ to swim, find the platform and climb onto it and the time to reach the platform (latency). The mouse was then left on the platform for $20 \mathrm{~s}$ until the start of the next trial. Mice that failed to find the platform within $60 \mathrm{~s}$ were removed from the water and placed on the platform for $20 \mathrm{~s}$ until the start of the next trial. On the fifth day, the mice were given only one block of four trials of the place test followed by one block of four trials of the spatial probe test. In the latter test, the platform was removed and the extinction of the learned behavior was evaluated as the sequential decline in the proportion of the distance swum in the quadrant of the missing platform, over the four 60-s trials. To control for the possible effect of swimming ability on the results, the swimming speed during each of the trials was calculated.

\section{Quantitative Assessment of PKC Isoforms}

Levels of the PKC isoforms $\gamma$ and $\alpha$ in the cytosolic and membrane fractions of hippocampal and cerebellar preparations were assayed after incubation of tissue slices with or without the cholinergic agonist, carbachol, using protocols modified (Steingart et al, 2000b; Shahak et al, 2003; Yaniv et al, 2004) from those of Burnette (1981) and Towbin et al (1979). As all these procedures have been described in detail previously (Shahak et al, 2003; Yaniv et al, 2004), only a brief description will be provided here. 
Tissues from each mouse were sliced uniformly with a McIlwain chopper and the slices were then distributed equally into two separate tubes. Incubations took place in the presence or absence of $1 \mathrm{mM}$ carbachol (carbamylcholine chloride, Sigma, St Louis, MO) at $32^{\circ} \mathrm{C}$ for $40 \mathrm{~min}$. After incubation, the tissues were washed twice with fresh buffer, homogenized, and then sedimented at $100000 \mathrm{~g}$ for $1 \mathrm{~h}$ at $4^{\circ} \mathrm{C}$, after which the supernatant solution containing the cytosolic fraction was frozen. The membrane pellet was resuspended and digested with $0.5 \%$ Triton X-100 (Sigma), then sedimented as previously described, and the supernatant solution was frozen.

Western blot analysis was carried out by gel electrophoresis of 10-15 $\mu \mathrm{g}$ aliquots of cytosolic and membrane protein using specific primary antibodies for each PKC subtype (Santa Cruz Biochemicals, Santa Cruz, CA) and an IgG HRP-conjugated (Bio-Rad) secondary antibody, exactly as described earlier (Yaniv et al, 2004; Shahak et al, 2003). We did not include internal standards of structural housekeeping' proteins ( $\alpha$-tubulin or $\beta$-actin) because many neuroteratogens, including phenobarbital, influence neuromorphological development (Eisch et al, 2000) and consequently cause alterations in the expression of these cytoskeleton proteins, unrelated to the neurobehavioral effects linked to specific cell signaling pathways. Instead, to ensure standardization, samples with and without carbachol were assessed in slices from the same animal and were run in proximity to each other on the same gel, so that the response was determined as the stimulation caused by carbachol within the preparations from each animal. Thus, any inherent differences other than the specific concentration of $\mathrm{PKC} \gamma$ are equally represented in both the numerator and denominator and do not contribute to the measured outcome, eliminating any differences in absolute concentrations on the gel that may be secondary to variable loads or nonspecific changes in protein expression; we further ensured that the OD readings for each lane were within the linear range of measurement. As an additional control, we evaluated receptor-induced translocation of $\mathrm{PKC} \alpha$, an isozyme that does not participate in hippocampal tasks such as spatial memory (Colombo et al, 1997). The lack of translocation observed for PKC $\alpha$ ensures that any alteration seen for $\mathrm{PKC} \gamma$ does not reflect artefacts in the Western blotting procedures.

\section{Cholinergic and Cell Injury Biomarkers in Cerebral Cortex and Brainstem}

These determinations were designed to assess the hippocampal specificity for the effects of phenobarbital and for the amelioration caused by subsequent nicotine treatment. Determinations were modeled on our earlier work showing global hippocampal upregulation of the presynaptic choline transporter and muscarinic receptors after prenatal phenobarbital exposure, changes that represent compensation for defective PKC $\gamma$ signaling (Steingart et al, 2000b; Yanai et al, 2003). Four cholinergic biomarkers were assessed: choline acetyltransferase (ChAT), $\left[{ }^{3} \mathrm{H}\right]$ hemicholinium-3 (HC3) binding to the choline transporter, nicotinic acetylcholine receptor (nAChR) binding, and $\mathrm{m}_{2} \mathrm{AChR}$ binding. Again, all the procedures have been described in detail previously (Qiao et al, 2003; Trauth et al, 1999) and will be presented only briefly here. Tissues were homogenized with a Polytron (Brinkmann Instruments, Westbury, NY) and aliquots were withdrawn for assessment of DNA and total protein. For ChAT activity, aliquots of homogenate (or buffer for the blanks) were incubated with $50 \mu \mathrm{M}\left[{ }^{14} \mathrm{C}\right]$ acetyl-coenzyme A (Perkin-Elmer Life Science, Boston, MA), and labeled acetylcholine was then extracted, counted and the activity determined relative to tissue protein (Smith et al, 1985). For measurements of radioligand binding, an aliquot of the same tissue homogenate was sedimented at $40000 \mathrm{~g}$, washed and resedimented, and the membrane pellet resuspended for the assays. For choline transporter binding, assays contained a final $\left[{ }^{3} \mathrm{H}\right] \mathrm{HC} 3$ concentration of $2 \mathrm{nM}$ and the nonspecific component was determined in the presence of $10 \mu \mathrm{M}$ unlabeled HC3 (Sigma). For $\mathrm{m}_{2} \mathrm{AChR}$ binding, aliquots of the same membrane preparation were incubated with $1 \mathrm{nM}\left[3^{3} \mathrm{H}\right]$ AFDX384 (Perkin-Elmer) with or without $1 \mu \mathrm{M}$ atropine (Sigma) to displace specific binding. For nAChRs, the ligand was $1 \mathrm{nM}\left[{ }^{3} \mathrm{H}\right]$ cytisine and the displacer was $20 \mu \mathrm{M}$ nicotine. Ligand binding was calculated relative to the amount of membrane protein.

DNA was determined in aliquots of the same tissue homogenates used for cholinergic biomarkers, using a fluorescent dye-binding method described earlier (Qiao et al, 2003). Samples were sonicated briefly (Virsonic Cell Disrupter, Virtis, Gardiner, NY) and Hoechst 33258 (Sigma) was added to a final concentration of $0.1 \mu \mathrm{g} / \mathrm{ml}$. Samples were then read in a spectrofluorometer using an excitation wavelength of $356 \mathrm{~nm}$ and an emission wavelength of $458 \mathrm{~nm}$, and were quantitated using standards of purified DNA.

\section{Data Analysis}

Data are presented as means and standard errors, with differences between treatments established by multivariate ANOVAs (data log transformed whenever variance was heterogeneous), followed where appropriate by the Tukey test for post hoc comparisons between groups. Sex effects were considered in the analysis and, in agreement with earlier work with prenatal phenobarbital treatment (Steingart et al, 2000a,b), the initial ANOVA did not identify any significant interactions of treatment $\times$ sex; accordingly, results from males and females are presented together. Significance for all tests was assumed at the level $p<0.05$. For convenience, some results are presented as the percent change from control values or as the percent stimulation over basal PKC activity; however, statistical tests were always performed on the original data.

\section{RESULTS}

Mice exposed prenatally to phenobarbital displayed impaired Morris water maze performance, requiring more time than controls to reach the platform (Figure 1a); the gap between the control and the treated offspring remained unchanged throughout the entire test period (no interaction of treatment $\times$ day). By itself, nicotine infusion had no effect on performance but nicotine totally reversed the deficits evoked by prenatal phenobarbital exposure. Differences in Morris maze performance did not reflect alterations in 
a

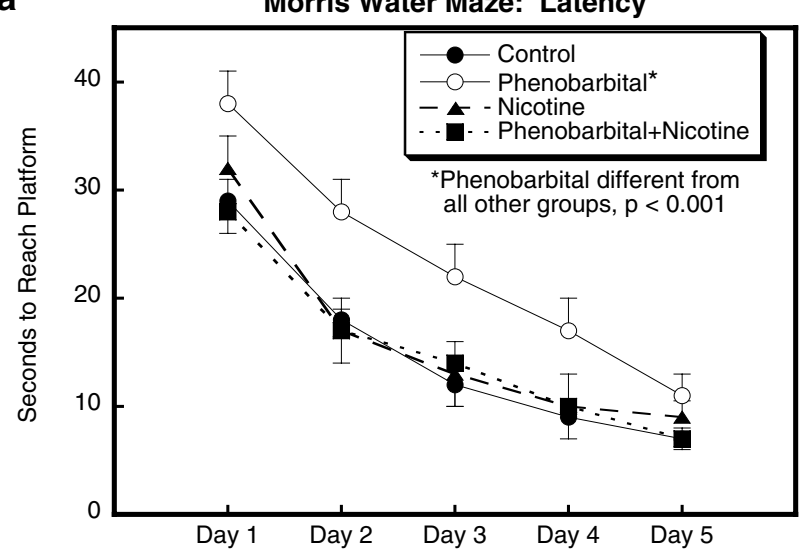

b Morris Water Maze: Spatial Probe Test on Day 5

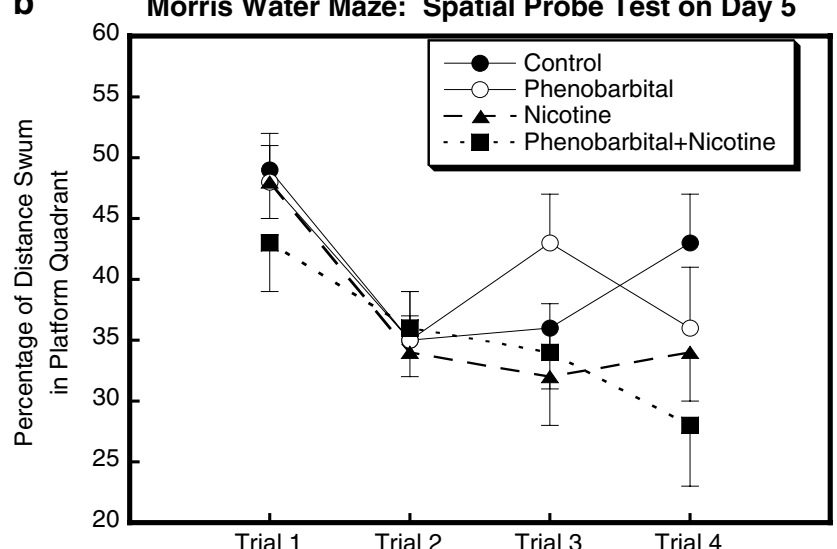

Figure I Effects of prenatal phenobarbital exposure and subsequent nicotine infusion on performance in the Morris water maze. Data for latency to find the platform (a) represents mean and SE obtained from 23 to 27 animals in each group, compiled from eight trials on days $1-4$ and four trials on day 5 (see Methods). In (b), the platform was removed and the proportion of swimming distance in the quadrant that had contained the platform was determined; values represent mean and SE obtained from 12 animals in each group, compiled across four trials conducted on day 5.

Table I Swimming Speed

\begin{tabular}{lcccc}
\hline Treatment & Trial I & Trial II & Trial III & Trial IV \\
\hline Control & $15.0 \pm 1.0$ & $16.4 \pm 1.2$ & $16.1 \pm 1.6$ & $11.4 \pm 1.1$ \\
Phenobarbital & $14.8 \pm 1.1$ & $17.5 \pm 2.2$ & $13.8 \pm 1.4$ & $10.8 \pm 0.9$ \\
Nicotine & $16.5 \pm 0.9$ & $17.0 \pm 1.2$ & $15.6 \pm 1.1$ & $13.8 \pm 1.0$ \\
Phenobarbital+nicotine & $14.8 \pm 0.6$ & $15.6 \pm 1.1$ & $14.5 \pm 0.8$ & $11.7 \pm 1.1$ \\
\hline
\end{tabular}

Values represent mean and SE of the swimming speed in $\mathrm{m} / \mathrm{min}$ during each of the four 60 s trials in the spatial probe test on day 5. Each group consisted of 12 animals. None of the differences is statistically significant.

swimming ability, as we did not find any differences in the total swimming speed when the platform was removed for the spatial probe test (Table 1). We also did not detect significant differences among groups for extinction in the spatial probe test (Figure 1b): across all groups, there was a progressive reduction in the time spent in swimming in the quadrant in which the platform had been located $(p<0.0001)$, but the trial-to-trial variability precluded finding significant intergroup differences in the extinction rate.

In keeping with earlier work (Shahak et al, 2003), stimulation of muscarinic acetylcholine receptors (mAChRs) with carbachol elicited translocation of $\mathrm{PKC} \gamma$ to the membrane fraction in the hippocampus of control mice (Figure 2a). Prenatal exposure to phenobarbital completely eliminated the response. Animals given nicotine infusions alone showed a normal response to carbachol, that is, indistinguishable from the response seen in control animals. The nicotine infusion restored the $\mathrm{PKC} \gamma$ response in the animals that had been exposed to phenobarbital prenatally, eliciting translocation that equaled or exceeded the control response. To verify the specificity of this effect, we performed a similar analysis for cytosolic $\mathrm{PKC} \gamma$ and found no carbachol-induced increase in the controls, and no effect of phenobarbital or nicotine alone or in combination (Figure 2a). Similarly, when we examined $\mathrm{PKC} \alpha$, an isoform that is not relevant to the behavioral test, there was no translocation elicited by carbachol and none of the treatments had an effect on either membrane or cytosolic components (Figure 2b).

To ascertain the regional specificity of the effects of prenatal phenobarbital and its amelioration by nicotine, we examined the PKC $\gamma$ response in the cerebellum, a region that is sparse in cholinergic projections and that does not play a major role in Morris maze performance. Carbachol did not elicit significant membrane translocation of $\mathrm{PKC} \gamma$ in control animals and phenobarbital, nicotine, or the combined treatment had no effect on either membrane or cytosolic activity (Figure 3 ).

In our earlier work with the prenatal phenobarbital model, we documented global upregulation of presynaptic and postsynaptic biomarkers of cholinergic activity in the hippocampus, findings that led to the current focus on $\mathrm{PKC} \gamma$ as the underlying defect in synaptic signaling (Steingart et al, 2000b; Yanai et al, 2003). In the current study, we expanded our investigations to the cerebral cortex and brainstem, regions that are also enriched in cholinergic nerve terminals and cell bodies (Cooper et al, 1996). To enable comparison across the two regions, values are presented as the percent change from control, and the corresponding control values are given in Table 2.

Prenatal phenobarbital treatment had no effect on nAChR binding in either region but nicotine administration in adulthood elicited the expected upregulation in both cerebral cortex and brainstem (Figure 4a). The effect of nicotine on nAChRs was not altered by prior exposure to phenobarbital, as upregulation was identical in the animals receiving the combined treatment. Accordingly, it is unlikely that prenatal phenobarbital exposure globally affected either the pharmacokinetics or pharmacodynamics of nicotine given in adulthood.

We then examined ChAT and HC3 binding, two biomarkers that delineate cholinergic presynaptic integrity and activity. ChAT, the enzyme responsible for acetylcholine biosynthesis, is a constitutive marker for cholinergic nerve terminals but its activity does not respond to changes in impulse flow, whereas $\mathrm{HC} 3$ binding does respond to increases or decreases in synaptic stimulation (Cooper et al, 


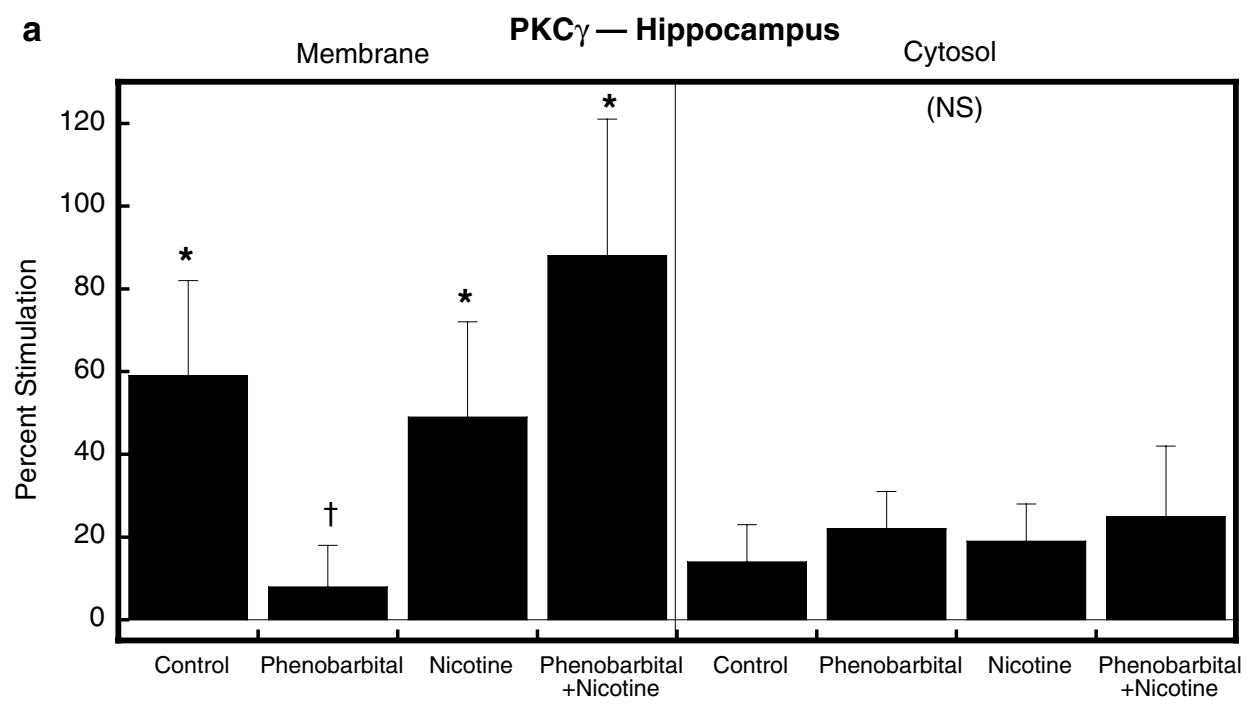

b

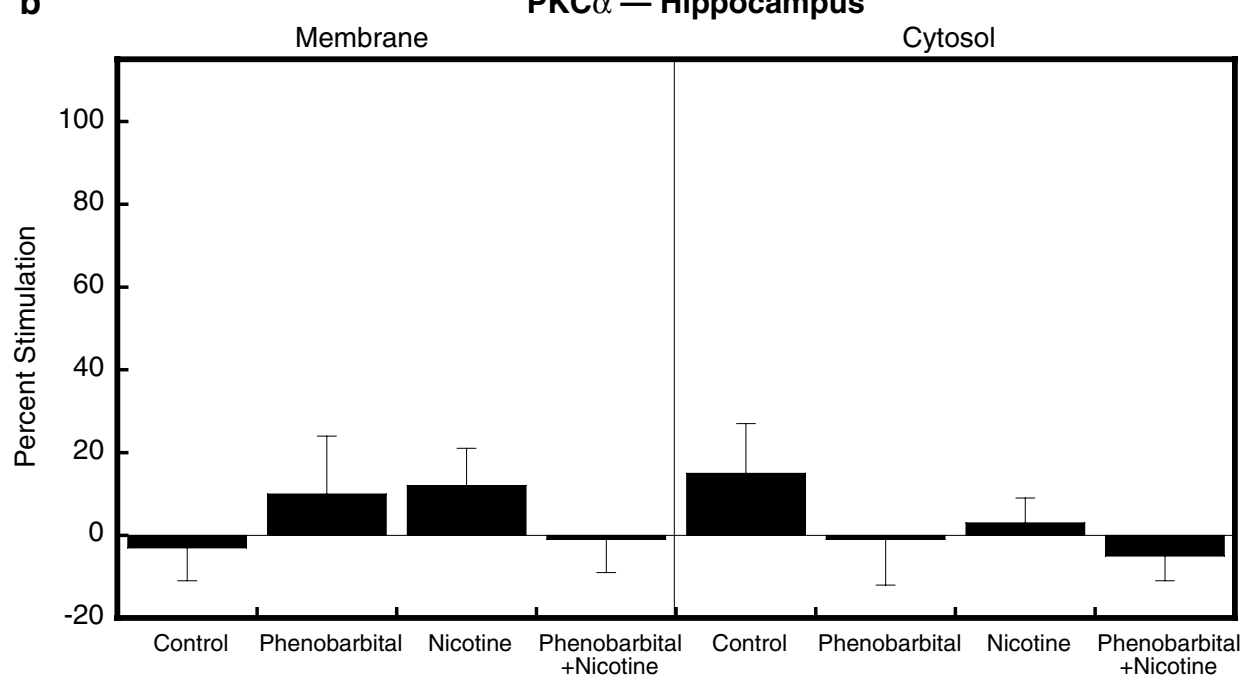

Figure 2 Effects of prenatal phenobarbital exposure and subsequent nicotine infusion on carbachol-induced translocation of PKC $\gamma$ (a) and PKC $\alpha$ (b) in the hippocampus. Data represent mean and SE obtained from 28 to 31 animals in each group. In (a), asterisks denote significant stimulation over basal PKC $\gamma ;$ the dagger indicates no significant stimulation, and significantly different from the other treatment groups. Abbreviation: NS, not significant. In (b), none of the responses is significant and none of the groups differs from the others.

1996; Klemm and Kuhar 1979; Simon et al, 1976; Zahalka et al, 1992, 1993). Prenatal phenobarbital treatment had no significant effect on either ChAT or HC-3 binding (Figure $4 \mathrm{~b}$ and $\mathrm{c}$ ), in contrast to the robust upregulation of the latter biomarker in the hippocampus as reported earlier (Steingart et al, 2000a,b). Phenobarbital elicited a small, but significant increase in $\mathrm{m}_{2} \mathrm{AChR}$ binding across the two brain regions and this effect was reversed by the subsequent nicotine treatment (Figure 4d); by itself, nicotine had no effect.

Finally, we examined the cerebral cortex and brainstem for cell damage biomarkers to evaluate whether neural cell injury contributes to the synaptic defects, and whether nicotine can reverse the injury. We focused on DNA content and the membrane/total protein ratio. As each neural cell contains a single nucleus with the same amount of DNA (Winick and Noble, 1965), the DNA content provides a measure of cell loss (Qiao et al, 2003). Similarly, neuritic outgrowth necessitates an increase in the membrane surface area of the cell and a corresponding rise in the membrane/ total protein ratio (Qiao et al, 2003). Since these measures involve all the cells and projections in a given region, they tend to change by small amounts but the consistency of the values renders even small changes readily detectable. Prenatal phenobarbital exposure evoked a significant decrement in DNA content with a larger effect in the cerebral cortex as compared to brainstem (Figure 5a). Although nicotine by itself had no effect, it significantly reversed the deficit caused by phenobarbital. However, the changes for membrane protein were quite different (Figure 5b): phenobarbital had no effect but nicotine reduced the membrane/total protein ratio regardless of whether animals had received prenatal vehicle or phenobarbital treatment. 


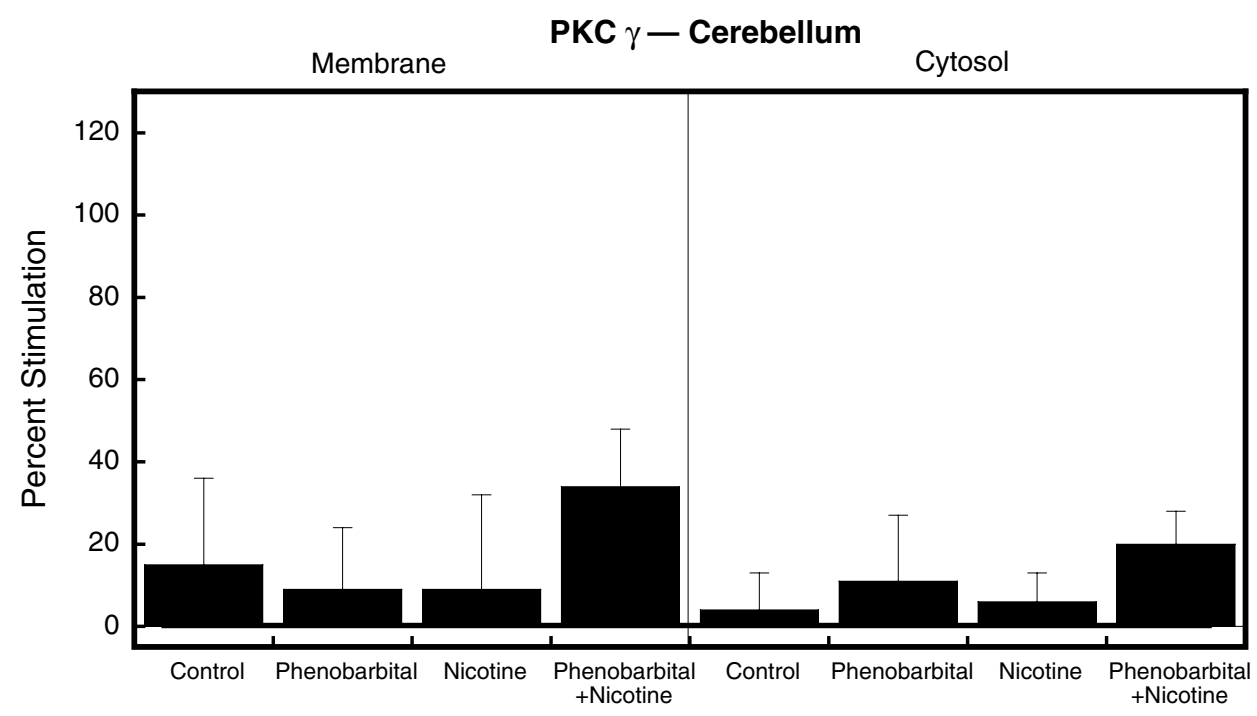

Figure 3 Effects of prenatal phenobarbital exposure and subsequent nicotine infusion on carbachol-induced translocation of PKC $\gamma$ in the cerebellum. Data represent mean and SE obtained from 9 to 10 animals in each group. None of the responses is significant and none of the groups differs from the others.

Table 2 Control Values for Biomarkers in Cerebral Cortex and Brainstem

\begin{tabular}{lcc}
\hline Measure & Cerebral Cortex & Brainstem \\
\hline nAChR binding (fmol/mg protein) & $4 I \pm 1$ & $63 \pm 3$ \\
ChAT (pmol/min/mg protein) & $826 \pm 14$ & $721 \pm 14$ \\
HC3 binding (fmol/mg protein & $25.0 \pm 1.5$ & $5.7 \pm 0.4$ \\
$m_{2}$ AChR binding (fmol/mg protein) & $460 \pm 6$ & $191 \pm 5$ \\
DNA content ( $\mu$ g) & $278 \pm 5$ & $94 \pm 1$ \\
Membrane/total protein (\%) & $48.6 \pm 0.4$ & $54.0 \pm 0.5$
\end{tabular}

Values represent mean and SE obtained from 22 to 24 animals in each group for the cerebral cortex and 10 to 12 animals in each group for the brainstem.

\section{DISCUSSION}

The present study demonstrates the efficacy of, and potential mechanisms for, nicotine therapy for the reversal of neurobehavioral birth defects in a defined model of septohippocampal cholinergic dysfunction. Mice exposed prenatally to phenobarbital demonstrated a complete loss of the cholinergic-induced translocation/activation of PKC $\gamma$ in the hippocampal membrane fraction, and a corresponding deficit in Morris maze performance. Both the effects of phenobarbital and the reversal by nicotine were highly specific. Phenobarbital did not alter PKC $\gamma$ translocation in the cerebellum, nor did it affect the activation of the nonbehaviorally relevant $\mathrm{PKC} \alpha$ isoform in the hippocampus. Similarly, the restitution of behavioral performance by nicotine administered in adulthood rectified the hippocampal PKC $\gamma$ defect without influencing hippocampal PKC $\alpha$ or cerebellar PKC $\gamma$.

Neuroteratogens generally act diffusely in the brain, resulting in multiple neurobehavioral deficits. In our studies, we focused on behavioral deficits related to a specific brain region (hippocampus) and innervation (cholinergic projections from the septum) so as to connect synaptic mechanisms of damage and repair to actual behavioral outcomes. Indeed, the septohippocampal cholinergic pathway provides an ideal model for this purpose, as spatial memory tasks such as the Morris maze are known to be controlled in large measure through this pathway (Nilsson et al, 1987; Olton and Papas 1979). In our earlier work with the prenatal phenobarbital model, we found profound upregulation of all aspects of presynaptic and postsynaptic activity in the hippocampus, including increases in HC-3 binding, acetylcholine release, $\mathrm{mAChR}$ binding, and $\mathrm{mAChR}$ linkages to signaling pathways other than PKC $\gamma$ (Yanai et al, 2003; Steingart et al, 2000b; Yaniv et al, 2004). Our recent discovery of the defect in $\mathrm{PKC} \gamma$ translocation as the critical step targeted by phenobarbital enabled us to pursue several approaches to reversing the neurobehavioral deficits, including grafting of cholinergic precursor cells into the hippocampus (Steingart et al, 2000b; Yanai et al, 2003) and lesioning of the inhibitory dopaminergic inputs to the hippocampus (Yanai et al, 1989). However, neither of these approaches is practicable for projected clinical use, whereas pharmacotherapy with nicotine is. Indeed, nicotine has been used to improve cognitive function in situations of cholinergic deficiency, such as in patients with neurodegenerative diseases (Newhouse et al, 1988), schizophrenia (Rezvani and Levin, 2004), or other situations exhibiting cognitive deficits (White and Levin, 1999). In animal models, nicotine improves hippocampal performance in aged rats with cognitive impairment or in young rats with cholinergic lesions (Levin, 1993). Furthermore, a recent study found that acute nicotine administration temporarily offsets the cognitive deficits induced by perinatal lead exposure (Zhou and Suszkiw, 2004), so that pharmacotherapeutic approaches to the reversal of neurobehavioral teratogenesis may, in fact, be widely applicable.

One key question raised by our findings is exactly how nicotine can rectify defective $\mathrm{PKC} \gamma$ signaling. Although 
nAChR Binding

ANOVA: Treatment, $p<0.0001$

Control vs. Nicotine, $p<0.0001$

a Control vs. [Phenobarbital+Nicotine], $p<0.0001$

Phenobarbital vs. Nicotine, $p<0.0001$
Phenobarbital vs. [Phenobarbital+Nicotine], $p<0.0001$

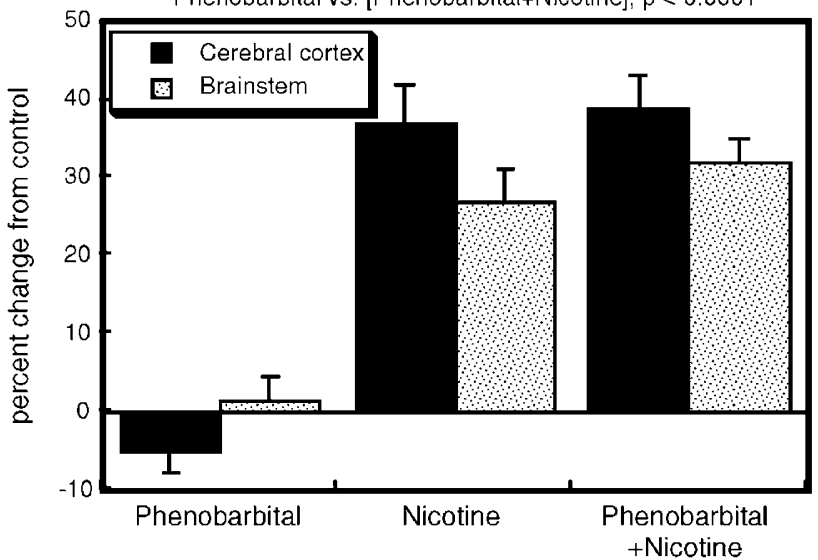

$\left[{ }^{3} \mathrm{H}\right]$ Hemicholinium-3 Binding

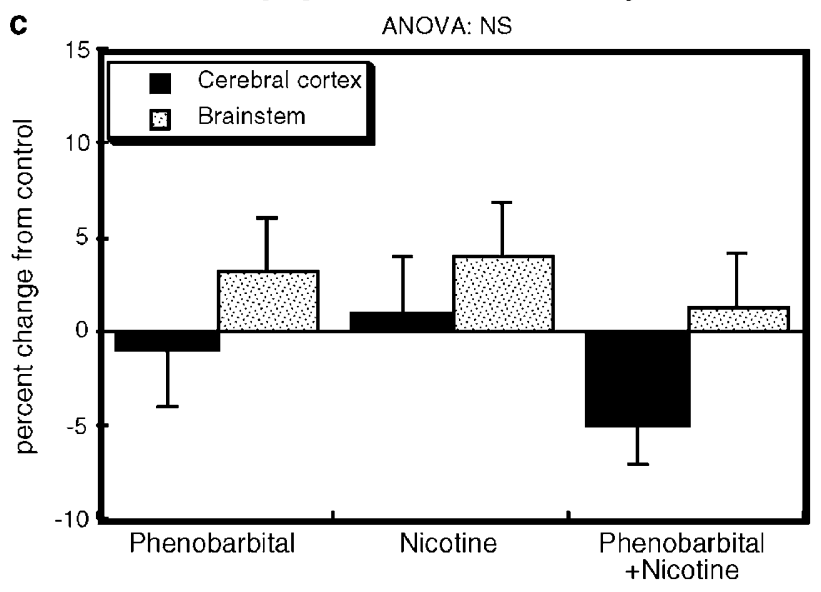

b
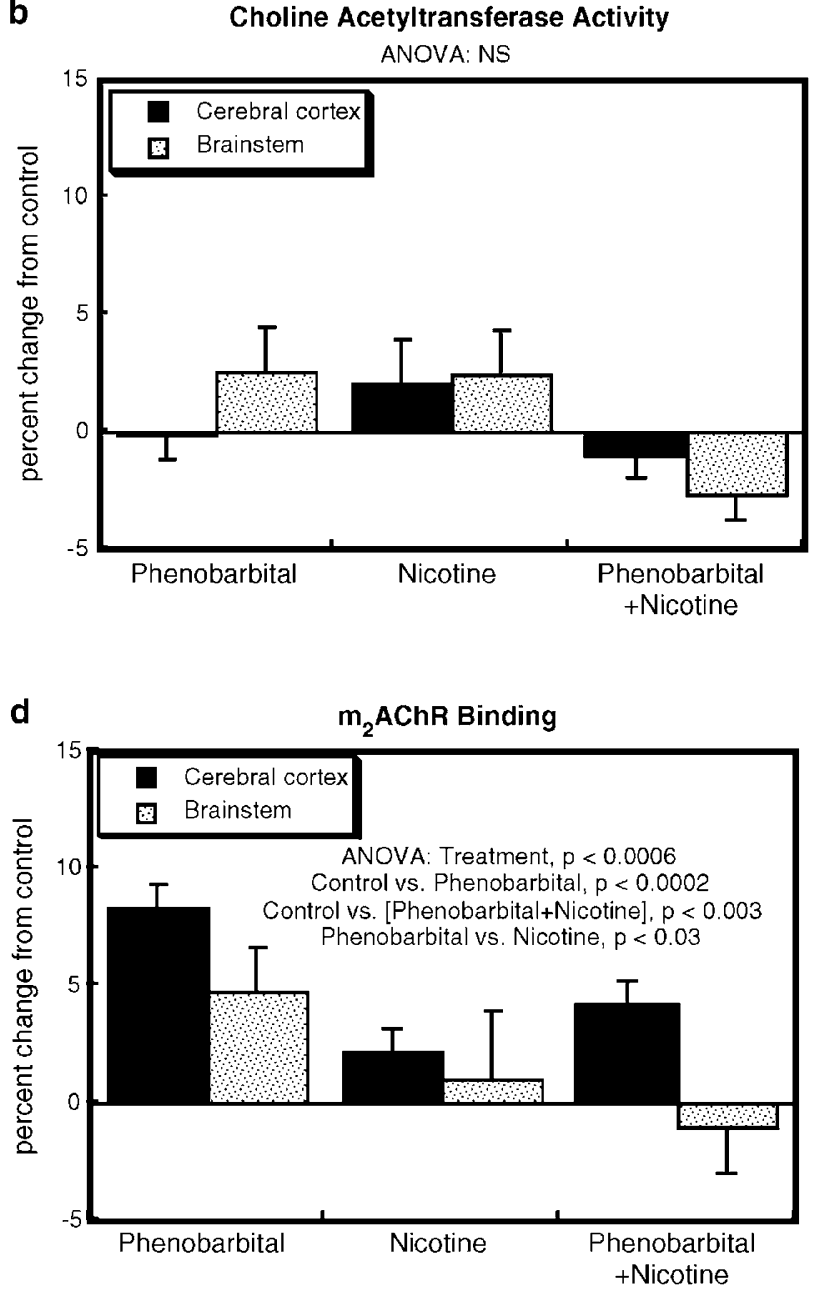

Figure 4 Effects of prenatal phenobarbital exposure and subsequent nicotine infusion on cholinergic biomarkers in cerebral cortex and brainstem: $n A C h R$ binding (a), choline acetyltransferase activity (b), $\left[{ }^{3} \mathrm{H}\right] \mathrm{HC} 3$ binding to the presynaptic choline transporter (c), and m2AChR binding (d). Values represent mean and SE obtained from 10 to 12 animals in each group for each region, presented as the percent change from control values (Table 2). ANOVA across all treatments and both regions appears at the top of each panel; lower-order tests for each region were not carried out because of the absence of treatment $\times$ region interactions.

mAChRs are primary regulators of PKC translocation/ activation (Van der Zee et al, 1993), nAChRs can also signal through PKC (Messing et al, 1989), and in addition, nAChRinduced release of other neurotransmitters further activate PKC pathways (Wonnacott, 1997). Both the $\alpha 7$ and $\alpha 4 \beta 2$ nAChR subtypes are implicated in the cognitive-enhancing effects of nicotine, including those mediated through septohippocampal cholinergic pathways (Rezvani and Levin, 2001). All of these contributing factors converge on the outcome seen here for the phenobarbital model: there was a clear $n A C h R-m A C h R$ connection in that the ability of nicotine to reverse behavioral teratogenesis was specifically related to the restoration of $\mathrm{mAChR}$-induced $\mathrm{PKC} \gamma$ translocation/activation.

Our findings in the cerebral cortex and brainstem reinforce the specificity of the effects of prenatal phenobarbital exposure and their reversal by nicotine. Unlike the situation in the hippocampus, where phenobarbital elicits
$70-100 \%$ increases in $\mathrm{HC} 3$ binding and mAChRs (Yanai et al, 2003; Steingart et al, 2000a, b; Yaniv et al, 2004), we did not find global upregulation of presynaptic and postsynaptic cholinergic activity markers in the other regions, with the exception of a small, but significant increase in $\mathrm{m}_{2} \mathrm{AChRs}$. The overwhelming impact of phenobarbital on cholinergic systems is thus on the septohippocampal cholinergic pathway and not on cholinergic circuits throughout the brain. That does not mean, however, that phenobarbital affects only this one circuit or only the hippocampus. When we examined general indices of cell damage, we found significant reductions in cell numbers (DNA content), especially in the cerebral cortex. This effect too was partially reversed by nicotine therapy. Since DNA reflects both neurons and glia, it is not possible to determine from this measurement alone whether neuronal replacement participates in the restoration of function, or whether the reversal of cell deficits represents 

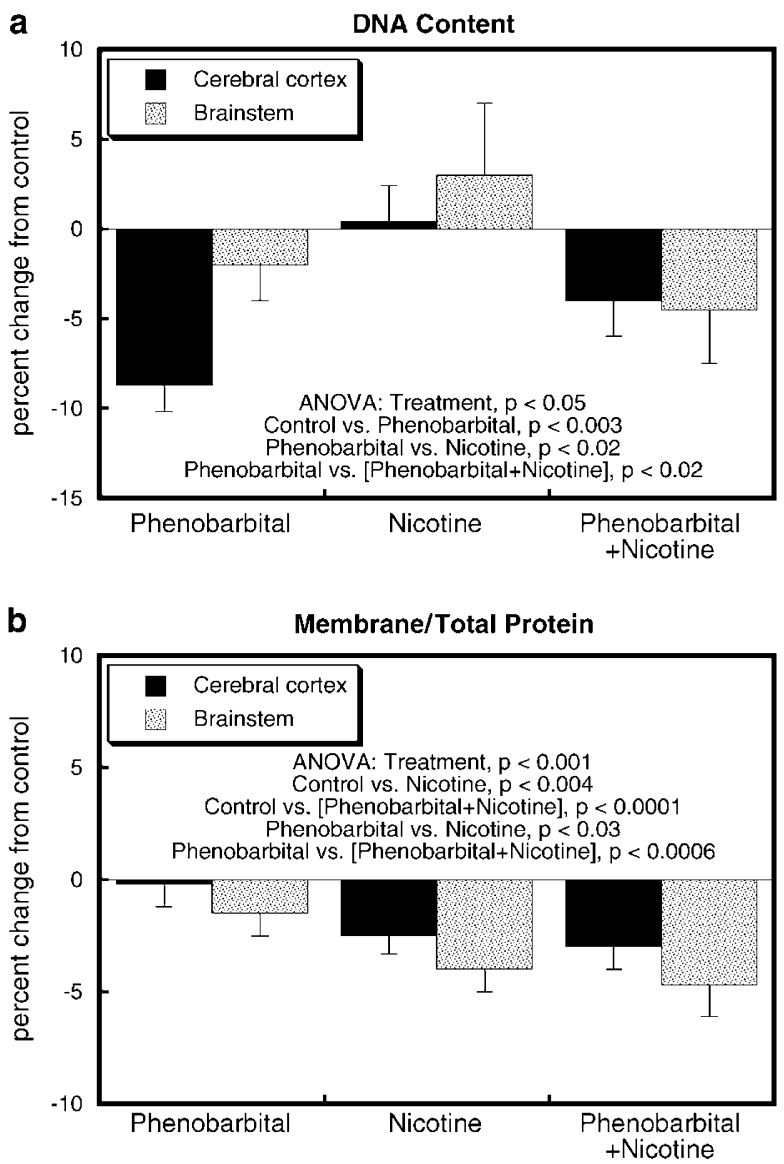

Figure 5 Effects of prenatal phenobarbital exposure and subsequent nicotine infusion on cell injury biomarkers in cerebral cortex and brainstem: DNA content (a) and membrane/total protein ratio (b). Values represent mean and SE obtained from 22 to 24 animals in each group for the cerebral cortex and 10 to 12 animals in each group for the brainstem, presented as the percent change from control values (Table 2). ANOVA across all treatments and both regions appears at the top of each panel; lower-order tests for each region were not carried out because of the absence of treatment $x$ region interactions.

gliosis. However, the small induction of cerebrocortical and brainstem $\mathrm{m}_{2} \mathrm{AChRs}$ was also reversed by nicotine therapy, suggesting that nicotine has additional actions that may offset neural damage and associated behavioral impairments in other areas and circuits. Although nicotine itself is a neuroteratogen (Slotkin, 1998), it has positive neurotrophic and neuroprotective effects in the adult brain (Belluardo et al, 2000). Accordingly, the ability of nicotine to offset the deleterious effect of prenatal phenobarbital on the number of cerebrocortical neural cells may represent prevention of apoptotic cell loss that may occur as a delayed consequence of prenatal phenobarbital exposure (Belluardo et al, 2000). However, not all of the effects of nicotine were beneficial, as we found indications of impairment of neuritic outgrowth in the nicotine-treated animals, as evidenced by a reduced membrane/total protein ratio.

Our findings indicate the need for follow-up studies in a number of areas. First, we did not assess whether nicotine therapy reverses the alterations in hippocampal cholinergic synaptic markers other than PKC, although our findings would suggest that this is likely to occur, given their reversal by grafting of cholinergic precursor cells into the hippocampus (Steingart et al, 2000b; Yanai et al, 2003); measurement of PKC translocation precludes the use of the same tissues for cholinergic biomarkers, so these will need to be evaluated separately. Second, we used $10 \mathrm{mg} / \mathrm{kg} /$ day of nicotine to accomplish our principal goal, establishing the feasibility of reversing phenobarbital neurobehavioral teratogenicity. Future studies need to establish the dose-response relationship, including measurement of plasma nicotine levels (given the much more rapid clearance of nicotine in the mouse as compared to humans), so as to select the lowest effective dose. Lastly, in light of the obvious liabilities of long-term nicotine therapy, the possibility needs to be explored that other cholinergic agonists, cholinesterase inhibitors, or cholinergic precursors will have similar therapeutic effects.

The current results show how knowledge of the specific neural pathway, regional target, and neurochemical defect underlying the actions of a defined neurobehavioral teratogen can lead to a rational, mechanistic approach to the design of therapies that restore behavioral function. Unlike surgical interventions such as neural grafting or lesioning of offsetting inputs, the potential application of nicotine therapy is entirely feasible and can be applied with existing techniques such as the nicotine transdermal patch. Finally, our results point to a potential contributory factor for the existence of human subpopulations that are especially vulnerable to the rapid onset of nicotine dependence upon experimentation with tobacco (DiFranza et al, 2002): individuals with cognitive impairment resulting from prenatal drug or toxicant insults may be able to rectify synaptic function through the self-administration of nicotine. These findings thus point to a convergence of studies of the origins, mechanisms, and therapies of neurobehavioral teratogenesis, with the propensity for stimulant abuse later in life.

\section{ACKNOWLEDGEMENTS}

This study was supported by USPHS grants HD 40820, ES07031, and by grant from Israeli Anti-Drug Authority. We thank Charlotte A Tate and Mandy M Cousins for technical assistance.

\section{REFERENCES}

Arroyo-Cabrales LM, Garza-Morales S, Hernandez-Pelaez G (1998). Use of prenatal phenobarbital in the prevention of subependymal/intraventricular hemorrhage in premature infants. Arch Med Res 29: 247-251.

Belluardo N, Mudo G, Blum M, Fuxe K (2000). Central nicotinic receptors, neurotrophic factors and neuroprotection. Behav Brain Res 113: 21-34.

Burnette WN (1981). 'Western blotting': electrophoretic transfer of proteins from sodium dodecyl sulfate - polyacrylamide gels to unmodified nitrocellulose and radiographic detection with antibody and radioiodinated protein A. Anal Biochem 112: 195-203.

Colombo PJ, Wetsel WC, Gallagher M (1997). Spatial memory is related to hippocampal subcellular concentrations of calciumdependent protein kinase $\mathrm{C}$ isoforms in young and aged rats. Proc Natl Acad Sci USA 94: 14195-14199. 
Cooper JR, Bloom FE, Roth RH (1996). The Biochemical Basis of Neuropharmacology. , 7th edn. Oxford University Press: New York, 518pp.

DiFranza J, Savageau JA, Rigotti NA, Fletcher K, Ockene JK, $\mathrm{McNeill} \mathrm{AD}$ et al (2002). Development of symptoms of tobacco dependence in youths: 30-month follow-up data from the DANDY study. Tob Control 11: 228-235.

Eisch AJ, Barrot M, Schad CA, Self DW, Nestler EJ (2000). Opiates inhibit neurogenesis in the adult rat hippocampus. Proc Natl Acad Sci USA 97: 7579-7584.

Golski S, Olds JL, Mishkin M, Olton DS, Alkon DL (1995). Protein kinase $\mathrm{C}$ in the hippocampus is altered by spatial but not cues discrimination: a component task analysis. Brain Res 676: 53-62.

Hanson K, Allen S, Jensen S, Hatsukami D (2003). Treatment of adolescent smokers with the nicotine patch. Nicotine Tob Res 5: 515-526.

Klemm N, Kuhar MJ (1979). Post-mortem changes in high affinity choline uptake. J Neurochem 32: 1487-1494.

Levin ED (1993). Development of treatments for toxicant-induced cognitive deficits. Neurotoxicol Teratol 15: 203-206.

Messing RO, Stevens AM, Kiyasu E, Sneade AB (1989). Nicotinic and muscarinic agonists stimulate rapid protein kinase $\mathrm{C}$ translocation in PC12 cells. J Neurosci 9: 507-512.

Morris R (1984). Developments of a water-maze procedure for studying spatial learning in the rat. J Neurosci Methods 11: 47-60.

Newhouse PA, Sunderland T, Tariot PN, Blumhardt CL, Weingartner $\mathrm{H}$, Mellow A et al (1988). Intravenous nicotine in Alzheimer's disease: a pilot study. Psychopharmacology (Berl) 95: 171-175.

Nilsson OG, Shapiro ML, Gage FH, Olton DS, Bjorklund A (1987). Spatial learning and memory following fimbria-fornix transection and grafting of fetal septal neurons to the hippocampus. Exp Brain Res 67: 195-215.

Nulman I, Laslo D, Koren G (1999). Treatment of epilepsy in pregnancy. Drugs 57: 535-544.

Olds JL, Golski M, McPhie DL, Olton DS, Mishkin M, Alkon DL (1990). Discrimination learning alters the distribution of protein kinase C in the hippocampus of rats. J Neurosci 10: 3707-3713.

Olton DS, Papas BC (1979). Spatial memory and hippocampal function. Neuropsychologia 17: 669-682.

Qiao D, Seidler FJ, Tate CA, Cousins MM, Slotkin TA (2003). Fetal chlorpyrifos exposure: adverse effects on brain cell development and cholinergic biomarkers emerge postnatally and continue into adolescence and adulthood. Environ Health Persp 111: 536-544.

Rezvani AH, Levin ED (2001). Cognitive effects of nicotine. Biol Psychiatry 49: 258-267.

Rezvani AH, Levin ED (2004). Nicotine-antipsychotic drug interactions and attentional performance in female rats. Eur $J$ Pharmacol 486: 175-182.

Rogel-Fuchs Y, Zahalka EA, Yanai J (1994). Reversal of early phenobarbital-induced cholinergic and related behavioral deficits by neuronal grafting. Brain Res Bull 33: 273-279.

Shahak H, Slotkin TA, Yanai J (2003). Alterations in PKCgamma in the mouse hippocampus after prenatal exposure to heroin: a link from cell signaling to behavioral outcome. Brain Res Dev Brain Res 140: 117-125.

Shim I, Ha Y, Chung JY, Lee HJ, Yang KH, Chang JW (2003). Association of learning and memory impairments with changes in the septohippocampal cholinergic system in rats with kaolin-induced hydrocephalus. Neurosurgery 53: 416-425 ; discussion 425.

Simon JR, Atweh S, Kuhar MJ (1976). Sodium-dependent high affinity choline uptake: a regulatory step in the synthesis of acetylcholine. J Neurochem 26: 909-922.

Slotkin TA (1998). Fetal nicotine or cocaine exposure: which one is worse? J Pharmacol Exp Ther 285: 931-945.
Slotkin TA (2002). Nicotine and the adolescent brain: insights from an animal model. Neurotoxicol Teratol 24: 369-384.

Smith DB, Goldstein SG, Roomet A (1986). A comparison of the toxicity effects of the anticonvulsant eterobarb (antilon, DMMP) and phenobarbital in normal human volunteers. Epilepsia 27: 149-155.

Smith PK, Krohn RI, Hermanson GT, Mallia AK, Gartner FH, Provenzano MD et al (1985). Measurement of protein using bicinchoninic acid. Anal Biochem 150: 76-85.

Steingart RA, Abu-Roumi M, Newman ME, Silverman WF, Slotkin TA, Yanai J (2000a). Neurobehavioral damage to cholinergic systems caused by prenatal exposure to heroin or phenobarbital: cellular mechanisms and the reversal of deficits by neural grafts. Brain Res Dev Brain Res 122: 125-133.

Steingart RA, Silverman WF, Barron S, Slotkin TA, Awad Y, Yanai J (2000b). Neural grafting reverses prenatal drug-induced alterations in hippocampal PKC and related behavioral deficits. Brain Res Dev Brain Res 125: 9-19.

Towbin H, Staehelin T, Gordon J (1979). Electrophoretic transfer of proteins from polyacrylamide gels to nitrocellulose sheets: procedure and some applications. Proc Natl Acad Sci USA 76: 4350-4354.

Trauth JA, Seidler FJ, McCook EC, Slotkin TA (1999). Adolescent nicotine exposure causes persistent upregulation of nicotinic cholinergic receptors in rat brain regions. Brain Res 851: 9-19.

Tuominen RK, McMillian MK, Ye H, Stachowiak MK, Hudson PM, Hong JS (1992). Long-term activation of protein kinase C by nicotine in bovine adrenal chromaffin cells. J Neurochem 58: $1652-1658$.

Valaes TN, Harvey-Wilkes K (1990). Pharmacologic approaches to the prevention and treatment of neonatal hyperbilirubinemia. Clin Perinatol 17: 245-273.

Van der Zee EA, Strosberg AD, Bohus B, Luiten PG (1993). Colocalization of muscarinic acetylcholine receptors and protein kinase $\mathrm{C}$ gamma in rat parietal cortex. Brain Res Mol Brain Res 18: $152-162$.

Wallace SJ (1984). Studies on the Effect of Anticonvulsant Drugs on the Developing Human Brain. Elsevier Science Publishers BV: Amsterdam. pp. 133-151.

Wehner JM, Sleight S, Upchurch M (1990). Hippocampal protein kinase $\mathrm{C}$ activity is reduced in poor spatial learners. Brain Res 523: 181-187.

White HK, Levin ED (1999). Four-week nicotine skin patch treatment effects on cognitive performance in Alzheimer's disease. Psychopharmacology (Berl) 143: 158-165.

Winick M, Noble A (1965). Quantitative changes in DNA, RNA, and protein during prenatal and postnatal growth in the rat. Dev Biol 12: 451-466.

Wonnacott S (1997). Presynaptic nicotinic ACh receptors. Trends Neurosci 20: 92-98.

Yanai J (1984). An animal model for the effects of barbiturate on the development of the central nervous system. Neurobehav Terarol 111-132.

Yanai J, Abu-Roumi M, Silverman WF, Steingart RA (1996). Neural grafting as a tool for the study and reversal of neurobehavioral birth defects. Pharmacol Biochem Behav 55: 673-681.

Yanai J, Fares F, Gavish M, Greenfeld Z, Katz Y, Marcovici G et al (1989). Neural and behavioral alterations after early exposure to phenobarbital. Neurotoxicology 10: 543-554.

Yanai J, Huleihel R, Izrael M, Metsuyanim S, Shahak H, Vatury O et al (2003). Functional changes after prenatal opiate exposure related to opiate receptors' regulated alterations in cholinergic innervation. Int J Neuropsychopharmacol 6: 253-265.

Yanai J, Pick CG (1988). Neuron transplantation reverses phenobarbital-induced behavioral birth defects in mice. Int $J$ Dev Neurosci 6: 409-416. 
Yaniv SP, Naor Z, Yanai J (2004). Prenatal heroin exposure alters cholinergic receptor stimulated translocation and basal levels of the PKC II and PKC isoforms. Brain Res Bull 63: 339-344.

Zahalka EA, Seidler FJ, Lappi SE, McCook EC, Yanai J, Slotkin TA (1992). Deficits in development of central cholinergic pathways caused by fetal nicotine exposure: differential effects on choline acetyltransferase activity and $\left[{ }^{3} \mathrm{H}\right]$ hemicholinium-3 binding. Neurotoxicol Teratol 14: 375-382.
Zahalka EA, Seidler FJ, Lappi SE, Yanai J, Slotkin TA (1993). Differential development of cholinergic nerve terminal markers in rat brain regions: implications for nerve terminal density, impulse activity and specific gene expression. Brain Res 601: 221-229.

Zhou M, Suszkiw JB (2004). Nicotine attenuates spatial learning deficits induced in the rat by perinatal lead exposure. Brain Res 999: 142-147. 